DOI: 10.15503/jecs20141-20-27

20

\title{
TOLERANCE FOR UNCERTAINTY IN ELDERLY PEOPLE
}

\author{
KHRYSTYNA KACHMARYK \\ Faculty of Psychology, Ivan Franko National University, \\ Universytetska Str 1, Lviv, Ukraine \\ E-mail address: hrustunka8@gmail.com \\ SOPHIA GRABOVSKA \\ Faculty of Psychology, Ivan Franko National University, \\ Universytetska Str 1, Lviv, Ukraine \\ E-mail address: soniah@ua.fm \\ KATERYNA OSTROVSKA \\ Faculty of Psychology, Ivan Franko National University, \\ Universytetska Str 1, Lviv, Ukraine \\ E-mail address: katerynaostrova@gmail.com \\ VIKTOR SYNIEV \\ Faculty of Special Pedagogy and Psychology, \\ Dragomanov National Pedagogic University, \\ 9 Turgenivska st., Kiev, Ukraine \\ E-mail address: ikpp@npu.edu.ua
}

\begin{abstract}
The aim of the study. The aim of the paper is a comparison of tolerance to uncertainty in two groups of elderly: the students of the University of the Third Age (UTA) and older people who are not enrolled but help to educate grandchildren. A relation to uncertainty was shown to influence on decision making strategy of elderly that indicates on importance of the researches.

Methods. To obtain the objectives of the paper the following methods were used: 1) Personal change readiness survey (PCRS) adapted by Nickolay Bazhanov and Galina Bardiyer; 2) Tolerance Ambiguity Scale (TAS) adapted by Galina Soldatova; 3) Freiburg personality inventory (FPI) and 4) The questionnaire of self-relation by Vladimir Stolin and Sergej Panteleev. 40 socially involved elderly people were investigated according the above methods, 20 from UTA and 20 who are not studied and served as control group.

Results. It was shown that relations of tolerance to uncertainty in the study group of students of the University of the Third Age substantially differ from relations of tolerance to uncertainty in group of older people who do not learn. The majority of students of the University of the Third Age have an inherent low tolerance for uncertainty, which is associated
\end{abstract}


with an increase in expression personality traits and characteristics in self-relation. The group of the elderly who are not enrolled increasingly shows tolerance of uncertainty, focusing on the social and trusting relationship to meet the needs of communication, and the ability to manage their own emotions and desires than a group of Third Age university students.

Conclusions. The results of experimental research of the third age university studen$t^{\prime}$ s peculiarities of the tolerance to uncertainty were outlined. It was found that decision making in the ambiguity situations concerning social interaction is well developed in elderly who do not study. The students of the University of Third Age have greater needs in conversation, social interaction than the control group and should learn to make decision in ambiguity or uncertainty situations.

Key words: tolerance, uncertainty, third age university, elderly people

\section{INTRODUCTION}

The healthy senior may experience substantial declines in cognitive function over time, even without clinical dementia. After peaking in middle age, the ability to make effective financial decisions declines (Kasten, 2014). In addition Gregory Kasten et al. underlined that criteria for determining prudent retirement income strategies is seniors researchers were directed to the problem of comparing young people and the elderly choices in the case of uncertainty and risk.

The few existing studies looking at decision making in older adults are inconclusive: some state that decision making abilities decline with age, while others disagree with this statement. For example, Stephanie Kovalchik with co-authors believe that older adults' overall decision making is similar to that of young adults (Kovalchik, 2005). From the other side, Agnieszka Tymula and co-authors identified several important age-related patterns in decision making under uncertainty (Tymula, 2008): 1) healthy elders between the ages of 65 and 90 were strikingly inconsistent in their choices compared with younger subjects. Just as the elderly show profound declines in cognitive function, they also show profound declines in choice rationality compared with their younger peers; 2) risk attitudes across the life span show an inverted U-shaped function, both elders and adolescents are more risk - averse than their midlife counterparts. Alec Sproten and co-workers show that older adults do not show a statistically significant difference between risk and ambiguity decisions (Sproten, 2010).

It is worthy to note that the population of elderly people should be divided on so-called "healthy" and "diseased" lines. Decision making strategy for diseased people (with schizophrenia, autism) substantially differs from that of healthy people (see for example Krug, 2013). Investigation of healthy elderly people showed that due to the aging process some changes in brain areas corresponding to making decisions occurs: Seyed Hadi Hosseini, Maryam Rostami, Yukihito Yomogida, Makoto Takahashi, Takashi Tsukiura, Ryuta Kawashima observed an age-related decrease in activity in the right inferior parietal lobule (Hosseini, Rostami, Yomogida, Takahashi, Tsukiura, \& Kawashima, 2010).

The above short review indicates that making decision strategy choice in elderly people is 1) age-dependent (Tymula, 2008); 2) is directly connected with 
relation to uncertainty (Sproten, 2010); 3) is dependent on "healthy" /"disease" lines of elderly (Krug, 2013). The question as participation of older people in various areas of socially meaningful life affects their ability to make choices in situations of uncertainty is poorly investigated in the recent literature. The aim of the current paper is a comparison of tolerance to uncertainty in two groups of elderly: the students of the University of the Third Age and older people who are not enrolled but help to educate grandchildren.

\section{EXPERIMENTAL METHOD}

The study group consisted of 40 persons, including 20 - student of the Third Age University, 20 - the elderly who are not enrolled. The elderly age was from 60 to 75 years. The investigated group contains 8 men and 12 women in the Third Age University and 7 men and 13 women in elderly who are not enrolled. The study was conducted individually with each of persons, which required the age characteristics of groups and in particular the number of students of the University of the Third Age today.

In our study we used 4 methods, namely:

1. Personal change readiness survey (PCRS) adapted by Nickolay Bazhanov and Galina Bardiyer (Nikiforov, 2010),

2. Tolerance Ambiguity Scale (TAS) adapted by Galina Soldatova (Chiker, 2007),

3. Freiburg personality inventory (FPI) (Krylov, 1997)

4. The questionnaire of self-relation by Vladimir Stolin and Sergej Panteleev (Stolin, Panteleev, 1988).

Method PCRS adapted by N. Bazhanov and G. Bardiyer was used to diagnose stress, arising from innovation, because no one can fully cope with the changes. Understanding the changes helps people protect themselves from stress in situations where they are most vulnerable.

Level of stress is distributed as follows: 10 points - low; $11-20$ points - average; 21-30 points - a high level of expression of the trait. Questionnaire contains 35 questions. The technique has 7 scales, namely: 1 . Passion; 2 . Ingenuity; 3 . Optimism; 4. Courage; 5 . Adaptability; 6 . Confidence; 7 . Tolerance of uncertainty.

Using this technique will allow us to assess the level of expression of tolerance to uncertainty in a group of students of the Third Age University and the control group.

Method TAS adapted by G. Soldatova was used in particular for the diagnosis of manifestations of intolerance to uncertainty. The methodology also provides three subscales. Calculating the amount of points for individual subscale allows us to identify the main source of intolerance to uncertainty: the novelty of the problem, its complexity or unsolvable problem.

Thus, the method contains 4 scales: 1 . The novelty of the problem; 2 . The complexity of the problem; 3 . Unsolvable problem. 4. Intolerance to uncertainty. Methodology contains 16 questions. The fourth scale is based on the summation of previous three. 
Freiburg personality inventory (FPI) is designed to diagnose mental personality traits, which are of particular importance for the process of social and professional regulation of behavior. The total number of questions in the questionnaire - 114. The scales of the questionnaire 1-9 are basic, while 10-12 - derivatives from them.

The questionnaire includes the following scales: 1 . Neuroticism; 2 . Spontaneous aggressiveness; 3 . Depression; 4 . Irritability; 5 . Sociability; 6 . The serenity; 7. Reactive aggression; 8. Shyness; 9. Openness; 10. Extraversion-introversion; 11. Emotional lability; 12 . Masculinity - femininity. The results of questionnaire are distributed as follows: 1-3 corresponds to low level of the feature; 4-6 - to average and 7-9 - to high level of the feature.

The questionnaire of self-relation by V. Stolin and S. Panteleev is built according to the developed hierarchical structure model of self-relation. The questionnaire allows detection of three levels of self-relation: global self-relation; self-relation, differentiated by self-esteem, self-sympathy, self-interest, and expectations to themselves; the level of specific actions in relation to "I". Method contains 57 questions. The questionnaire includes the following scales: Scale $S$ - global self-relation, integral feature of " for" or "against" their own "I" investigated. Scale I - self-esteem. Scale II - self-sympathy. Scale III - the expected ratio from others. Scale IV - self-interest. The questionnaire also contains seven scales aimed measuring the severity of the installation to certain domestic actions to the "I": 1 - self-confidence, 2 - the ratio of the other, 3 - self-acceptance, 4 - self-sequence, 5 - self-incrimination, 6 - self-interest, 7 - self-understanding.

To analyze the results we used the following methods of mathematical processing: correlation analysis, comparative analysis (paired t-Student test) and carried out a quantitative analysis of the results.

The main hypotheses:

1. We assume that most of the students of the University of the Third Age will be exposed to a low level of tolerance for uncertainty, which is associated with an increase of intolerance for uncertainty as well as personality traits and self-relation in studied group.

2. We assume that a group of elderly people who do not study to a greater extent have a tolerance for uncertainty, focusing the social and trusting relationship to meet the needs of communication, than the students of the university of third age.

\section{ANALYSIS OF EXPERIMENTAL RESULTS}

To test our main hypotheses, we used the results of quantitative analysis and correlation analysis results.

Based on the results of quantitative analysis it was found that only $10 \%$ of the study group of students of the University of the Third Age has high level expression of tolerance for uncertainty, $15 \%$ - the average level of tolerance for uncertainty, and $75 \%$ - the low level of tolerance for uncertainty. These are shown in Figure 2.1.

We can draw conclusions about that at this stage, our main hypothesis is partially confirmed, because most of the studied group of students of the University 
of the Third Age are characterized by low expression of tolerance to uncertainty, which in turn means their extremely troubled relationship to the absence of clear answers, while not known goals and objectives, or when these tasks may not be able to be finished.

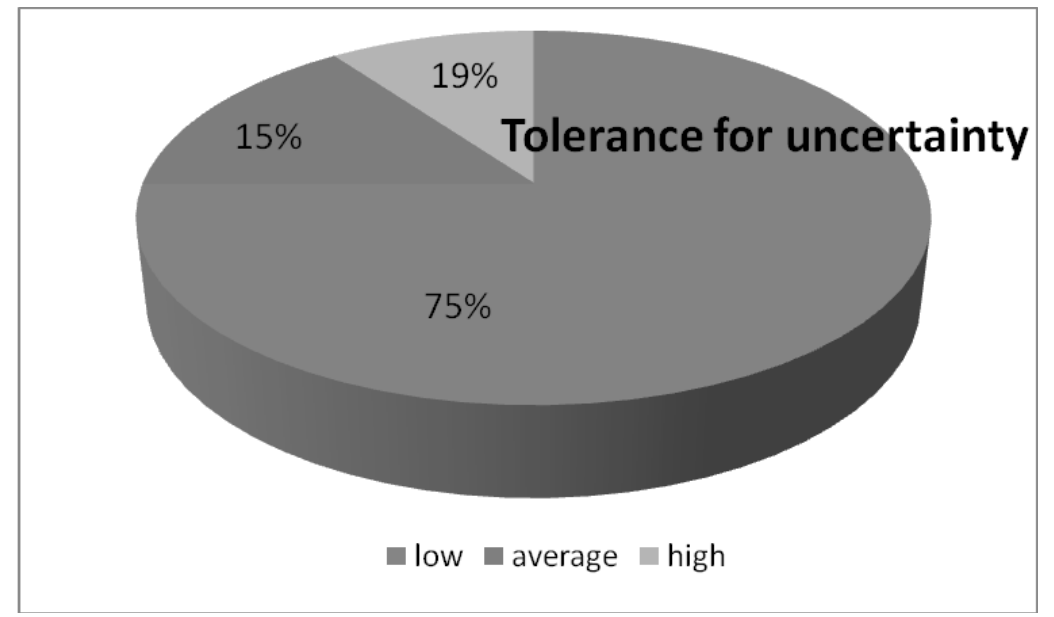

Fig. 2.1. Distribution of the University of the Third Age students on scale "Tolerance for uncertainty" according to PCRS method adapted by N. Bazhanov and G. Bardiyer.

Source: Authors` research.

Based on the results of the correlation analysis, the scale of "tolerance of uncertainty" of PCRS method is inversely correlated with scales of adaptation techniques TAS by G. Soldatova "Novelty problems" $(r=-0,58$ at $p<0.05)$, "The complexity of the problem" $(r=-0,74$ at $p<0.05)$, "unsolvable problems" $(r=-0,46$ at $p$ $<0.05)$, "intolerance to uncertainty" ( $r=-0,74$ at $p<0.05)$, Freiburg scale personality questionnaire FPI «serenity» $(r=-0,57$ at $p<0.05)$, scales of the questionnaire self-relation by V. Stolin and S. Panteleev "Global self-relation" $(r=-0,60$ at $p<$ $0.05)$,"Authosympathy" $(\mathrm{r}=-0.60$ at $\mathrm{p}<0.05)$, "self-understanding" $(\mathrm{r}=-0,50$ at $\mathrm{p}$ $<0.05)$. The data presented in Figure 2.2.

From the results of the correlation analysis, we see that there is a correlation between tolerance to intolerance of uncertainty and performance uncertainty, balance, global self-attitude, autosympathy and self-understanding. This may indicate that with increasing severity of the new task, reducing stress resistance and reducing overall self-esteem, a sense of calm and composure in a situation of uncertainty will decrease.

Thus, our first hypothesis is that the majority of students of the University of the Third Age will be exposed to a low level of tolerance for uncertainty, which is associated with an increase in expression of criteria to intolerance of uncertainty and personality traits and characteristics of self-relation - fully confirmed, based on quantitative and correlation analysis.

To test our further hypothesis, we used the comparative analysis (T -Student's test). 


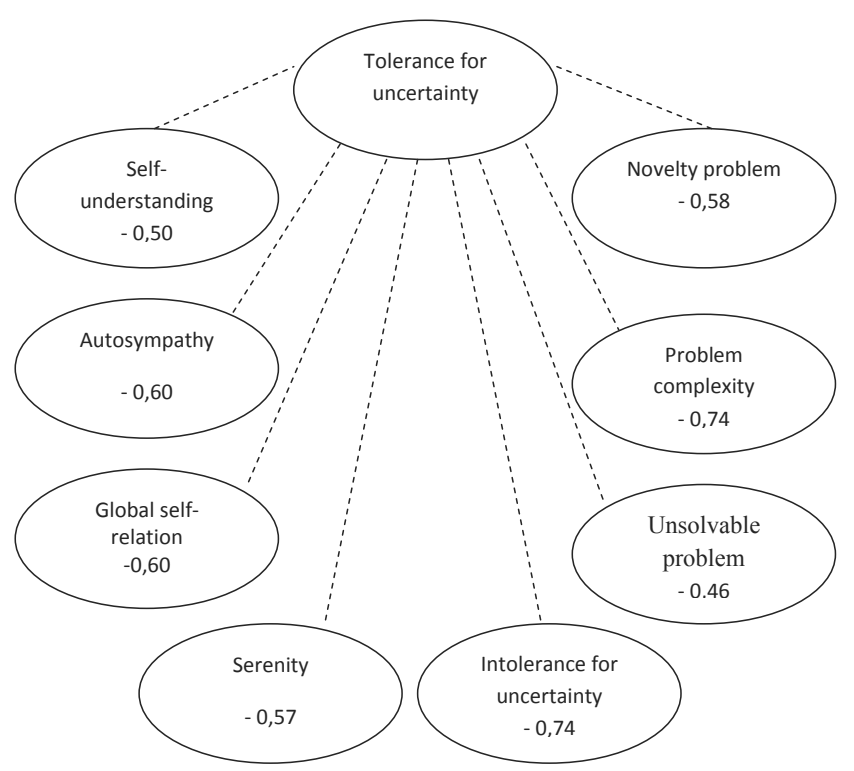

Fig. 2.2. The correlation parameter "Tolerance of uncertainty" of PCRS method with parameters of other methods (group surveyed students of the University of the Third Age).

Source: Authors`research.

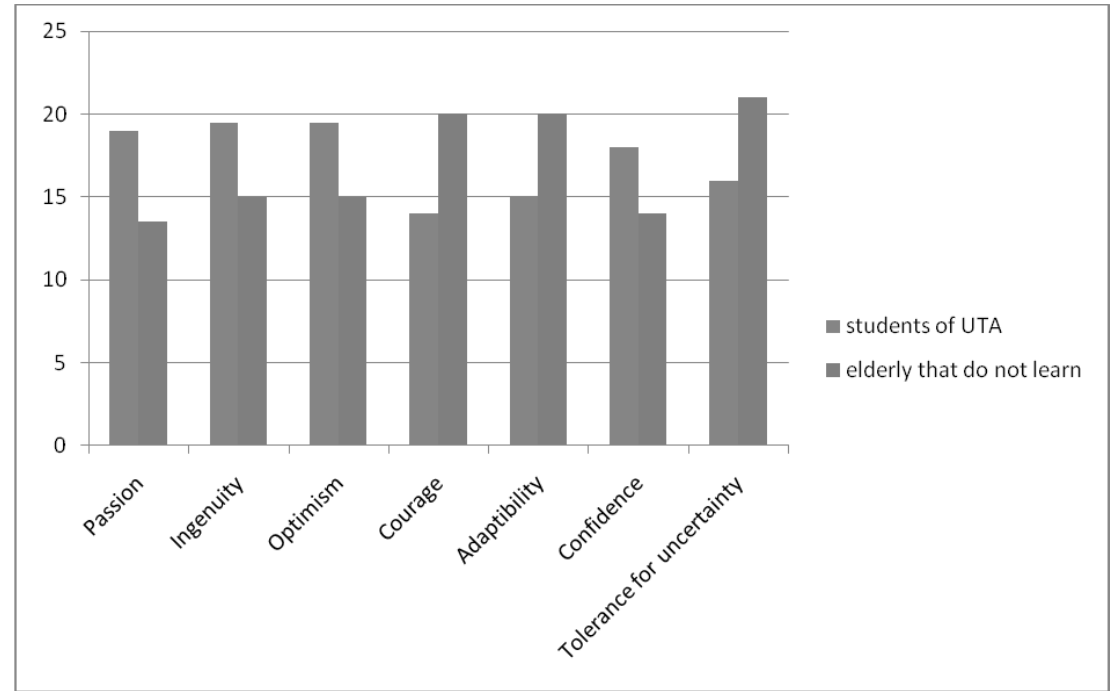

Fig. 2.3. A comparison between group of students of the University and the Third Age and group of elderly persons who are not enrolled in the features detection of tolerance for uncertainty. Source: Authors' research.

Comparing between groups of surveyed students of Third Age university and older people who do not learn showed that in a group of elderly subjects who do not study increasingly found tolerance to uncertainty, courage and adaptability. 
Group surveyed students of the University of the Third Age is increasingly characterized by passion, creativity, optimism and confidence. That is, it may indicate that a group of students of the University of the Third Age is more vigorous, with the best skills out of the difficult situations, more confident, but to a lesser degree seeking something new, less flexible and more fear related to uncertainty. So, at this time our second hypothesis partially confirmed. These results are shown in Figure 2.3.

Comparison between a group of university students and older people who do not learn turned out that almost all the indicators self-relation of University students is higher than in the control group, except for self-control and self-understanding. This may indicate that the higher the rating itself and expectations of a positive evaluation of oneself in others are more characteristic for a group of students of the University of the Third Age, but they at least are able to manage their own desires and needs. So, at this time our second hypothesis partially confirmed. These results are shown in Figure 2.4.

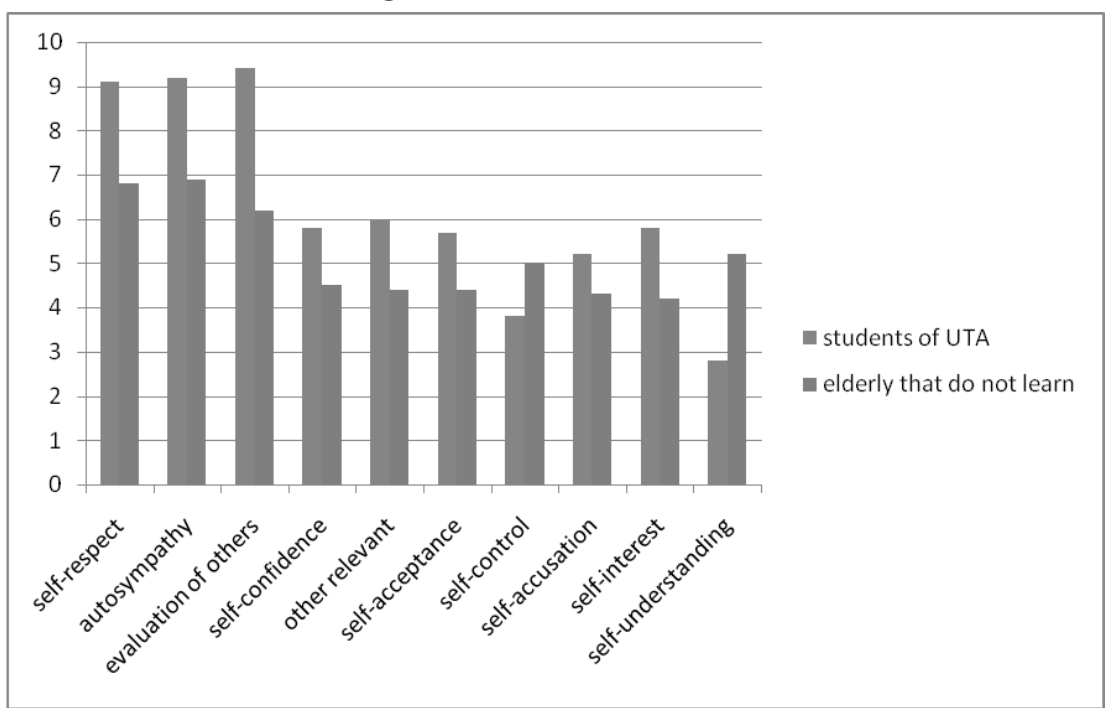

Fig. 2.4. A comparison between group of students of the University and group of older people who do not learn in the specifics self-relation.

Source: Authors' research.

So our second hypothesis that in the group of elderly subjects who do not study, to a greater extent be found tolerance for uncertainty, focusing on the social and trusting relationship to meet the needs of communication, and the ability to manage their own desires and emotions than in group of university students confirmed by a comparative analysis ( $\mathrm{t}$-Student test). Thus decision making in the ambiguity situations concerning to social interaction is well developed in elderly who do not study but help to educate grandchildren. The students of the University of Third Age have greater needs in conversation, social interaction than the control group and should be taught to make decisions in ambiguity or uncertainty 
situations. The above statements should be accounted by scientific council of the University of Third Age for improvement of education program.

\section{CONCLUSIONS}

After analyzing the survey results, we can conclude that the majority of students of the University of the Third Age have an inherent low tolerance for uncertainty, which is associated with an increase in expression of criteria to intolerance of uncertainty and personality traits and characteristics in self-relation. The group of the elderly who are not enrolled increasingly shows tolerance of uncertainty, focusing on the social and trusting relationship to meet the needs of communication, and the ability to manage their own emotions and desires than a group of Third Age university students. Relations of tolerance to uncertainty in the study group of students of the University of the Third Age substantially differ from relations of tolerance to uncertainty in group of older people who do not learn due to personality traits and characteristics of self-relation.

It was found that decision making in the ambiguity situations concerning social interaction is well developed in elderly who do not study. The students of the University of Third Age have greater needs in conversation, social interaction than the control group and should learn to make decision in ambiguity or uncertainty situations. These statements should be accounted by scientific council of the University of Third Age for improvement of education program.

\section{REFERENCES}

Chiker, V.A. (2007) 18 программ тренингов: Руководство для профессионалов [18 program trainings: Guide for professionals], Sankt-Peterburg: Речь.

Hosseini, S. M., Rostami M., Yomogida Y., Takahashi M., Tsukiura T., \& Kawashima R. (2010). Aging and decision making under uncertainty: behavioral and neural evidence for the preservation of decision making in the absence of learning in old age. Neuroimage, 52(4), 1514-1520. doi: 10.1016/j. neuroimage.2010.05.008

Kasten, G. W., \& Kasten, M. W. (2014). The Impact of Aging on Retirement Income Decision Making. Journal of Finansial Planning, 1, 60-69.

Kovalchik, S., Camerer, C., Grether, D., Plott, C., \& Allman, J. (2005). Aging and decision making: A comparison between neurologically healthy elderly and young individuals. Journal of Economic Behavior \& Organization, 58(1), 79-94.

Krug, A., Cabanis, M., Pyka, M., Pauly, K., Kellermann, T. (2013). Attenuated prefrontal activation during decision-making under uncertainty in schizophrenia: A multi-center fMRI study. Schizophrenia Research, 12. doi: 10.1016/j.schres.2013.11.007.

Krylov, A.A. (1997) Практикум по экспериментальной и практической психологии: Учеб. пособие [Workshop on experimental and applied psychology: textbook], Sankt-Peterburg: Издательство С.-Петербургского университета.

Nikiforov, G.S. (2010) Психология менеджмента: практикум [Psychology of management: workshop], Sankt-Peterburg: Речь.

Stolin, V.V. and Panteleev, S.R. (1988). Опросник самоотношения: Практикум по психодиагностике [Questionnaire of the self-relation: workshop on psychodiagnostics], Moscov: Просвещение.

Sproten, A., Diener, C., Fiebach, C., Schwieren, C. (2010). Aging and decision making: How aging affects decisions under uncertainty. Discussion Paper Series, 508, 1-22.

Tymula, F., Belmaker, L. A. R., Ruderman, L., Glimcher, P. W., and Levy, I. (2014). Like cognitive function, decision making across the life span shows profound age-related changes. PNAS, 110 (42), 17143-17148, doi: 10.1073/pnas.1309909110. 